ARTIGO

Recebido em: 13/01/2017

Aceito em: 29/05/2017

\title{
Fontes de informação jurídica
}

\author{
Sources of legal information
}

\section{Resumo}

Enfoca a informação jurídica, discutindo suas características e importância para os juristas, com ênfase nas fontes de informação jurídica, ressaltando a legislação, jurisprudência e doutrina, além de destacar a rapidez com que elas se renovam, tornando a informação, ainda recente, ultrapassada. Apresenta as principais fontes de produção da informação jurídica e a comunidade de usuários. Sugere, então, estratégias para o bibliotecário jurídico melhor gerenciar suas atividades diante das mudanças e da diversidade dos novos suportes informacionais, a fim de alcançar a plena satisfação e valorização dos usuários.

Palavras-chave: Informação jurídica. Fontes de informação jurídica. Comunidade jurídica. Fontes de informação jurídica - Brasil.

\begin{abstract}
It focuses on legal information, discussing its characteristics and importance for jurists, with emphasis on the sources of legal information, highlighting legislation, jurisprudence and doctrine, as well as highlighting the speed with which they renew themselves, making the information, still recent, outdated. It presents the main sources of production of legal information and the user community. It then suggests strategies for the legal librarian to better manage their activities in the face of the changes and diversity of the new informational media in order to reach the full satisfaction and appreciation of the users.
\end{abstract}

Keywords: Legal Information. Sources of legal information. The legal community. Sources of legal information - Brazil.

v. 22 , n. $50,2017$. p. $76-90$

ISSN 1518-2924
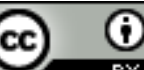

sta obra está licenciada sob uma Licença Creative Commons 


\section{INTRODUÇÃo}

O conhecimento movimenta a sociedade, por meio dele evoluímos tanto ao adquirir e produzir novos conhecimentos. Atualmente, esse ciclo se tornou tão proeminente na sociedade da informação. Sociedade essa, caracterizada pelo fluxo constante na produtividade. Na perspectiva de Valentim (2002), a informação, dentro dessa sociedade se tornou a base da economia, vista como infraestrutura para se armazenar, processar e acessar, independente de qual área seja.

No mundo globalizado, é fundamental estar atento às constantes inovações oriundas do ambiente externo às organizações, objetivando atingir a melhoria da sua capacidade competitiva e produtiva. É importante que os juristas tenham em mãos informações correntes e atualizadas, capazes de eliminar as suas incertezas, podendo auxiliá-los nas fundamentações de suas decisões. Suas necessidades de informação não se limitam apenas aos processos judiciais, mas, também, a toda proliferação do panorama político-social, econômico, legislativo e jurisprudencial.

Neste contexto, a informação jurídica é vista como esclarecimento útil para o progresso e desenvolvimento da cidadania, e por meio dela, os profissionais do direito produzem conhecimentos nos quais fundamentam suas análises e adotam decisões que regularão a vida em sociedade. Passos (1994, p.363) retrata esse cenário ao mencionar

[...] a ciência do Direito abrange, praticamente, todas as facetas da vida humana, mesmo antes do seu nascimento até depois da sua morte. Na verdade, o Direito rege a vida em sociedade, deliberando sobre as complexas relações humanas, procurando estabelecer a disciplina social.

Dentro do universo da informação jurídica, este trabalho busca conhecer suas fontes de informação instituídas publicamente no Brasil, mediante a análise do nível de valor agregado, e da qualidade da informação nelas disponibilizadas, nos diversos suportes informacionais, a fim de subsidiar as instituições e os profissionais que trabalham com área jurídica no Brasil.

\section{METODOLOGIA}

A pesquisa constitui-se qualitativa, de caráter exploratório, utilizando como procedimento metodológico a pesquisa bibliográfica para coleta de dados como base aportes da Ciência da Informação, em especial, voltados para os seguintes assuntos: "fontes de Informação", "fontes de informação na internet" "informação jurídica", "fontes de informação jurídicas".

Gil (2008) destaca a pesquisa bibliográfica como primeiro passo para a revisão de conceitos, um dos objetivos deste trabalho, constituindo-se como base de qualquer pesquisa científica. De acordo com Boaventura (2012), o trabalho de revisão de literatura são estudos que analisam a produção bibliográfica dentro de uma temática, dentro de um recorte de tempo, fornecendo um panorama geral, a fim de estabelecer as linhas de ação para abordar o assunto ou problema e gerar novas ideias úteis.

Para o desenvolvimento deste estudo, a fim de proporcionar melhor entendimento sobre sua execução, foram utilizados livros e artigos científicos sobre os temas abordados, de modo a reunir dados dispersos, buscando a apropriação de informações sobre os conceitos abordados. 


\title{
3 INFORMAÇÃO JURÍDICA
}

Muito se tem enfatizado sobre a importância da informação, como principal insumo das organizações. Com a explosão quantitativa da informação, ocorrida logo após a Revolução Industrial, fenômeno comum a todas as áreas do conhecimento, a produção e a circulação do conhecimento expandiram-se vertiginosamente, tornando fundamental a execução eficiente do planejamento na ampliação e manutenção das coleções de bibliotecas.

$\mathrm{Na}$ área jurídica, podemos observar o crescimento do número de documentos publicados nos últimos anos. A produção de informação jurídica tem alcançado grandes proporções com a intensificação da elaboração doutrinária e da publicação de leis. Em decorrência da evolução tecnológica, muitas são as situações novas a exigirem dos juristas e dos elaboradores das leis uma maior produção de normas e interpretação doutrinária para melhor tratar as condutas inovadoras.

Na perspectiva de Capurro e Hjorland (2007), informação é algo inerente ao homem, percebido de acordo com a sua subjetividade e acima de tudo, relativo ao seu contexto social. Para os autores, isso ocorre visto que os homens se organizam de acordo com determinadas situações sociais e que cada uma dessas situações (subjetivas por natureza) acontecem com intenções específicas e relativas a determinados grupos, daí a dificuldade de se precisar o que seria informação. Sua definição não pode ser dar isoladamente. Uma vez que a informação tem sido valorizada, são muitos os conceitos que surgem e o tema vem sendo debatido profusamente ${ }^{1}$.

Diante desse contexto, o termo "informação" assume diversos contextos, dentre estes, a informação jurídica. A literatura especializada no Brasil apresenta algumas definições, Alonso (1998 apud Rezende 2004, p. 175, grifo nosso) conceitua sob dois aspectos.

\begin{abstract}
Informação jurídica, sob o aspecto genérico, pode ser conceituada como qualquer dado ou fato, extraído de toda e qualquer forma de conhecimento da área jurídica, obtido por todo e qualquer meio disponibilizado e que pode ser usado, transferido ou comunicado sem a preocupação de estar integrado a um contexto. É um dado ou qualquer elemento identificado em sua forma bruta que por si só não conduz a uma compreensão de determinado fato ou situação.

Informação jurídica sob o aspecto de documentação organizada, é o produto da análise dos dados existentes em toda e qualquer forma de conhecimentos obtidos na área jurídica, devidamente registrados, classificados, organizados, relacionados e interpretados dentro de um contexto para transmitir conhecimento e permitir a tomada de decisões de forma otimizada. A disponibilidade desses dados, devidamente trabalhados, é feita a partir de meios manuais/mecânicos/magnéticos aos interessados.
\end{abstract}

Na opinião de Passos (1994, p.363), esse tipo de informação é definido como:

\footnotetext{
1 São variados os autores que de dedicam a conceituar a Informação, dentre alguns destacamos: Le Coadic (1996, p.5) que define a mesma como sendo "um conhecimento inscrito (gravado) sob a forma escrita (impressa ou numérica), oral ou audiovisual". Já Silva \& Ribeiro (2002) apontam que a informação: "Refere-se um fenômeno humano e social que compreende tanto o dar forma a ideias e a emoções (informar), como a troca, a efetiva interação dessas ideias e emoções entre seres humanos (comunicar), identifica um objeto científico, que vem a ser um conjunto estruturado de representações mentais e emocionais codificadas (signos e símbolos) e modeladas com//pela interação social, passíveis de serem registradas num qualquer suporte material (papel, filme, banda magnética, disco compacto, etc.) e, portanto, comunicadas de forma assíncrona e multidirecionada".
} 
[...] toda unidade de conhecimento humano que tem a finalidade de embasar manifestações de pensamento de jurisconsultos, advogados, legisladores, desembargadores, juízes e todos aqueles que lidam com a matéria jurídica, quando procuram estudar (do ponto de vista legal) ou regulamentar situações, relações e comportamentos humanos, ou ainda quando interpretam e aplicam dispositivos legais.

Barros (2004) considera que a informação jurídica é um tipo de informação útil para a promoção da cidadania. Por meio dela, os profissionais de Direito produzem conhecimentos nos quais baseiam suas análises e tomam decisões que regularão a vida em sociedade.

Os meios pelos quais a informação jurídica se manifesta acompanham as mudanças das evoluções tecnológicas, revestindo-se das mais variadas formas tais como: homepage, correio eletrônico, periódicos eletrônicos, sites dos tribunais que disponibilizam suas jurisprudências, diários oficiais, livros, monografias, comunicação interpessoal, súmulas, coletânea de textos legais, base de dados etc.

0 volume da informação jurídica produzida e solicitada tem-se expandido aceleradamente em decorrência das constantes alterações na legislação, o que consequentemente altera o conjunto sistemático do Direito que, por sua vez, gera inúmeras jurisprudências.

Rezende (1998) afirma claramente que o panorama da informação jurídica tem sofrido grandes inovações, além de ser o que mais cresce e se desenvolve no Brasil. Basta lembrar que se por um lado, o antigo Código Civil Brasileiro foi aprovado em 1916 e ficou em vigor por quase noventa anos; por outro lado, o Novo Código Civil, em vigor desde 11 de janeiro de 2002, já possui mais de 200 artigos a serem alterados, sem falar no número de emendas que a nossa Constituição possui e das outras Leis modificadas como a Nova Lei de Falências.

Já o antigo Código de Processo Civil Brasileiro estava em vigor desde 11 de janeiro de 1973, ficou em atuação por 43 anos, sendo substituído pelo novo Código de Processo Civil (CPC) o qual foi aprovado pelo Plenário em 17 de dezembro de 2014, mas teve o texto modificado na Câmara dos Deputados, forçando uma nova votação no Senado em 15 de dezembro de 2015, no total, 13 artigos foram modificados. Passando a vigorar em 18 de março de 2016, levando quase cinco anos de debates no Congresso.

Neste contexto, Passos e Barros (2009) apontam a longevidade como uma das características mais importantes da informação jurídica. Por exemplo, apesar de revogados, todos os atos realizados durante a vigência dos códigos mencionados, ambos permanecem sendo estudados sob sua ótica. Desta forma, por longos anos ainda serão produzidas jurisprudência fundamentada nos seus textos.

Em contrapartida, as alterações na legislação não significam que os textos revogados ficarão obsoletos, pois como afirma Lopez-Muñiz (1984), a informação jurídica possui validade quase que permanente, interessando ao jurista não apenas a legislação em vigor, mas também às anteriores. Os preceitos revogados poderão ser aplicados aos atos jurídicos que se tenham originado sob a sua vigência, perdurando, pois, além da própria revogação. Portanto, não convém prescindir da intensidade de uso dos documentos jurídicos mais antigos pelo simples fato de esses não serem usados durante certo tempo. Isso não quer dizer que a informação não possua mais nenhuma utilidade ou valor no futuro.

Uma característica que diferencia a informação jurídica das outras é o seu aspecto de longevidade, haja vista que na contemporaneidade elas são processadas de um modo muito rápido.

Martinho (2006, p. 91) caracteriza a informação jurídica a partir dos seguintes itens: 
a) grandes volumes de informação e rapidez da sua desatualização, face a um constante crescimento e criação de novas fontes (novas leis, novas áreas do Direito, constante produção de doutrinas);

b) grande diversidade de fontes de informação;

c) proliferação de suportes de informação (bases de dados, CDROMs, WWW); Interação com outras áreas do conhecimento (Filosofia, Sociologia, Economia, História, Informática, Política, etc.);

d) público-alvo exigente e diversificado (pluralidade de finalidades da informação pretendida);

e) necessidade de grande rigor e precisão da sua conservação no documento jurídico, qualquer que seja o seu suporte;

f)necessidade de grande rapidez e rigor na sua transmissão, de modo a assegurar a sua correta utilização e aplicação, de acordo com as últimas alterações ocorridas e a garantir a fiabilidade da mensagem transmitida.

Burton \& Kleber apud Oberhofer (1991) compararam a meia-vida de uma substância radioativa com a taxa de envelhecimento da literatura. Destaca: "ao contrário de uma substância radioativa que se transforma em uma substância totalmente modificada à medida que degenera a literatura, simplesmente deixa de ser de utilizada; envelhece, mas não perde sua capacidade de ser usada".

Os usuários da informação jurídica são bastante diversificados, pois esse tipo de informação é imprescindível para o exercício e prerrogativa de garantia dos direitos individuais. Todo cidadão depende, frequentemente, dessa informação.

A informação jurídica é originada fundamentalmente por um tripé informacional, distinto: Legislação, Doutrina e Jurisprudência. Legislação é o conjunto normativo que regula a convivência social. A Doutrina é o conjunto de princípios expostos nas obras de direito, em que se firmam teorias ou se fazem interpretações sobre a ciência jurídica. E a Jurisprudência é a sábia interpretação e aplicação das leis a todos os casos concretos que se submetem a julgamento da justiça, que produz sentenças no primeiro grau, ou acórdãos e súmulas nos Tribunais (MIRANDA, 2004).

Guimarães (1993) menciona, ainda, como documentos legislativos: a resolução, a portaria, a circular e a ordem de serviço. 0 autor explica que a informação legislativa possui forma específica e estrutura interna preestabelecida; de maneira oposta da informação doutrinária, que por sua vez não possui regras rígidas de apresentação, sendo produzida, na maioria das vezes, sob a forma dissertativa e monográfica.

Já Machado (2000) chama atenção no tocante à Legislação e à Jurisprudência. Sua recuperação inadequada ou incompleta gera insatisfação aos seus usuários, como pode causar danos, especialmente aos juristas, englobando todos aqueles que se utilizam dela e as partes. Quanto à Doutrina, não exige uma recuperação exaustiva, mas, no mínimo, razoável, o que igualmente demonstra em grande volume de informações que, mesmo em parte, necessitam ser atualizadas.

\section{FONTES DE INFORMAÇÃO}

O conceito de fontes de informação é bastante complexo, pois pode incluir uma infinidade de documentos desde manuscritos e publicações impressas e eletrônicas, além de fotografias, obras de arte, como também objetos, amostras minerais etc.

Beckman e Silva (1967) consideram fontes de informação como o lugar de origem, onde a informação adequada é extraída e transmitida ao usuário. Seu conhecimento não é atributo exclusivo ao bibliotecário, mas só este possui o dever 
de conhecê-las todas, nas suas características intrínsecas e no seu modo de utilização em relação à demanda das diversas classes profissionais.

Genericamente falando, as fontes de informação podem ser divididas em três categorias:

a) Documentos primários: são na maioria das vezes aqueles produzidos com a influência direta de um autor, abordando informações novas ou novas interpretações de ideias e/ou fatos, acontecimentos. Para Grogan apud Mueller (2000), as fontes primárias são dispersas e desordenadas no tocante à produção, à divulgação e ao controle, tornando difícil sua identificação e localização. Temos como exemplos de fontes primárias: legislação, relatórios, trabalhos apresentados em congressos e conferências, teses, dissertações, patentes, normas técnicas, artigo de periódicos, traduções, livros, entre outros.

b) Documentos secundários: possuem a função de facilitar o acesso aos documentos primários dispersos e apresentam a informação organizada segundo um plano definido. São representados, por exemplo, pelas bases de dados, bibliografias, índices, anuários, biografias, catálogos de bibliotecas, dicionários, enciclopédias, manuais, internet, tabelas, coletâneas de jurisprudências e/ou legislação etc. A título de exemplo, na área jurídica, temos: Bibliografia Brasileira de Direito, coletâneas de jurisprudências, coletâneas de legislação, entre outros.

c) Documentos terciários: são aqueles que têm a função de guiar os leitores para os documentos primários e secundários. No entanto, na sua maioria não trazem nenhum conhecimento ou assunto como um todo, ou seja, apenas são sinalizadores de localização ou indicadores sobre documentos primários e secundários. São apresentadas por meio das bibliografias de bibliografias, bibliotecas, centros de documentação e informação, catálogos coletivos, guias de literatura, diretórios, entre outros. Temos como exemplo, na área jurídica, a Bibliografia Brasileira de Direito.

\subsection{Fontes de informação jurídica}

Entende-se por fontes de informação jurídica o lugar de onde o bibliotecário extrai a informação a fim de repassá-la à comunidade jurídica ou ao cidadão comum, que a busque, visando atender aos interesses de suas pesquisas.

Na opinião de Passos e Barros (2009), as fontes de informação jurídicas exercem um papel relevante no desenvolvimento das ações do profissional de direito. Para fins documentais, os sistemas de informações e as bases de dados desempenham para auxiliar tanto o bibliotecário quanto para o usuário final na busca e recuperação da informação jurídica.

Consideramos fontes de informação jurídica toda publicação jurídicolegislativa (leis; emendas constitucionais; constituições; decretos, códigos; estatutos; diários oficiais; jurisprudências; súmulas; bases de dados; pessoas, repertórios, vocabulários jurídicos, pareceres, periódicos, coletâneas de textos de dispositivos legais, bibliotecas jurídicas etc.) produzidas por órgãos governamentais (senado federal; câmaras dos deputados; assembleias legislativas; câmara de vereadores; tribunais; ministérios públicos etc.).

As fontes de informação jurídica são indispensáveis aos profissionais de Direito na execução das suas atividades, pois ao jurista para atingir a uma resolução, são necessárias horas exclusivamente dedicadas à pesquisa, a fim de fundamentar a decisão, consultando as Leis pertinentes, jurisprudências que a interprete e a bibliografia que disponibilize soluções, após todo esse apanhado de informações, será possível obter uma decisão para solucionar o fato em questionamento.

Como já foi citada anteriormente, a informação jurídica se manifesta por intermédio de: legislação, doutrina e jurisprudência. 


\subsubsection{Legislação}

Legislação é o conjunto normativo que regula o convívio social, disciplinando relações materiais e, ao mesmo tempo, tutelando direitos imateriais. Como afirma Alonso (1998), a legislação sofre constantes adaptações às reivindicações da sociedade: conceitos antigos se tornam ultrapassados com a invenção de novas ferramentas legais, porém, nem por isso devem ser relegados a um plano secundário pelo valor temporal ou mesmo histórico.

Segundo Barros (2004), a Lei é a principal fonte do Direito, compreendida como uma norma geral, escrita, que segue um rito peculiar de elaboração procedente do processo legislativo pela entidade competente.

Andreta (2004) destaca ainda mais essa importância da legislação quando se refere aos países de tradição jurídica romanista, como o Brasil, onde a legislação toma lugar de evidência no âmbito das fontes formais do Direito. Como consequência, sua produção acontece em grandes proporções, causando a chamada proliferação legislativa.

A legislação, também intitulada conjunto de leis, diz respeito à união de atos normativos originado de autoridade competente. Tais atos são apresentados em diferentes tipos, conforme Marques Junior (1997, p. 165) enquadra no âmbito da informação legislativa, hierarquicamente, os seguintes diplomas legais:

a) Constituição - conjunto de normas fundamentais, constantes de documento escrito, solene e inalterável por lei ordinária, reguladoras da própria existência do Estado, de sua estrutura, órgãos e funções, do modo do exercício e limites da soberania, dos seus fins e interesses fundamentais, das liberdades públicas, direitos e deveres dos cidadãos;

b) Emenda constitucional - texto que altera, em geral parcialmente, disposições da Constituição vigente, a fim de tornála mais viável, ou de incorporar-lhe disposições apropriadas ao desenvolvimento técnico e social da Nação;

c) Lei complementar - ato normativo que visa a dar desdobramento disciplinar a preceito da Constituição que não seja autoaplicável;

d) Medida provisória - ato normativo expedido exclusivamente pelo Presidente da República, em caso de urgência e relevância, com força de lei, submetido de imediato ao Congresso Nacional, com perda de eficácia, desde a edição, se não for convertido em lei no prazo de trinta dias contados de sua publicação;

e) Lei ordinária - qualquer norma jurídica elaborada pelo Poder Legislativo em sua atividade comum e típica;

f) Lei delegada - lei elaborada pelo Chefe do Executivo, por delegação expressa do Poder Legislativo, mediante resolução que especifica o conteúdo e os termos do exercício dessa prerrogativa; g) Decreto - ato legislativo de competência exclusiva do Chefe do Executivo, destinado a prover situações gerais ou individuais, previstas de modo explícito ou implícito pela legislação.

A informação jurídico-legislativa se manifesta, ainda, por intermédio das Resoluções, Códigos, Estatutos, Portarias, Consolidações, Regulamentos etc. Estas são consideradas componentes básicos e imprescindíveis, pois mesclam de atos normativos são instrumentos relevantes para os profissionais que atuam no campo jurídico.

O que mais dificulta trabalhar com a informação legislativa é a revogação implícita ou subentendida, ou seja, o que está ou não em vigor, quando da inexistência de revogação expressa. De acordo com Alonso (1998), apenas o especialista poderia informar, e mesmo ele, pode ter dificuldade em identificar as 
duas categorias já que a revogada implícita somente pode ser, na realidade, determinada por via judicial ou via legislativa.

Todavia as obras de legislação são imprescindíveis, pois o conjunto de atos normativos é uma ferramenta essencial ao exercício legal da profissão de qualquer jurista.

\subsubsection{Doutrina}

0 termo doutrina é oriundo do latim doctrina, do verbo doceo - ensinar, instruir. De acordo com Diniz (1992), etimologicamente, a doutrina é decorrente do pensamento sistematizado sobre determinado problema, com a finalidade precípua de ensinar, impondo uma ortodoxia, isto é, um pensamento tido como correto por determinado ponto de vista ou grupo. Nesta senda, a doutrina advém da atividade científico-jurídica, ou seja, procedente das pesquisas e estudos científicos elaborados pelos juristas, na análise e sistematização das normas jurídicas, na geração das definições dos conceitos jurídicos, na interpretação das leis, facilitando e orientando a tarefa na aplicação do Direito.

A Doutrina é o conjunto de princípios expostos nas obras de Direito, em que se firmam teorias ou se fazem interpretações acerca de uma norma ou decisão jurídica. Nessa mesma concepção, Cunha e Cavalcanti (2008) define doutrina como a reunião de documentos teóricos sobre um assunto que abrange conceitos, ideias e opiniões que os autores apresentam e defendem no estudo e no ensino do Direito. Diante desse contexto, constatamos que cada autor transmite seu entendimento ou posicionamento sobre determinado assunto. Essa fonte de informação jurídica constitui um espaço para análise, críticas e reflexões da legislação e da jurisprudência, buscando facilitar a compreensão dos textos legais, a fim de contribuir como embasamento teórico para a própria atuação jurídico-legislativa.

Doutrina não é considerada por muitos autores, uma fonte do Direito, por ela não ser dotada de coercibilidade, ou seja, o que os doutrinadores falam não possui efeito vinculante, que é um requisito indispensável ao conceito de fonte.

Reale (1998) destaca, pelo fato de a doutrina não ser considerada uma fonte do Direito, mas nem por isso deixa de ser considerada uma das molas propulsoras, e a mais radical das forças diretoras do ordenamento jurídico. Na realidade, a sua função é de outra natureza, como se depreende da comparação entre o que é produzido pelas fontes e o que é indagado pela doutrina.

Andreta (2004) considera a doutrina um espaço para análise, reflexão e discussão da legislação e jurisprudência, destacando seus valores e imperfeições, tem também por objetivo auxiliar a compreensão dos textos legais, sendo útil ao embasamento teórico para a própria atuação jurídico-legislativa.

As obras de doutrina são apresentadas por intermédio dos livros, artigos de periódicos, teses, dissertações, monografias e papers apresentados em congressos, sendo, assim, produzidas por especialistas na área jurídica.

\subsubsection{Jurisprudência}

O termo "jurisprudência" advém do latim Juris, direito e prudentia, sabedoria. Tecnicamente, jurisprudência significa "a ciência da lei", a qual consiste numa decisão reiterada diversas vezes pelo tribunal.

A jurisprudência, como fonte de informação, fornece subsídios para interpretação e aplicação das leis a todos os casos concretos que se submetem a julgamento da justiça, que produz sentenças no primeiro grau, ou acórdãos e súmulas nos Tribunais.

No entendimento de Montoro, a palavra "jurisprudência" possui várias acepções na linguagem técnica jurídica, apresentando três significados distintos: 
a) pode indicar a "Ciência do Direito", em sentido estrito, também denominada "Dogmática Jurídica" ou "Jurisprudência";

b) pode referir-se ao conjunto de sentenças dos Tribunais, em sentido amplo e abranger tanto a jurisprudência uniforme como a contraditória;

c) em sentido estrito, "jurisprudência" é apenas o conjunto de sentenças uniformes; nesse sentido, falamos em "firmar jurisprudência" ou "contrariar a jurisprudência". (2000, p. 352 ).

De acordo com Cunha e Cavalcante (2008) e Montoro (2000), a jurisprudência é elucidada como um conjunto de decisões judiciais referentes a casos semelhantes e que tenham acontecido isoladamente, porém uniforme e constantemente.

Em sentido estrito, a palavra jurisprudência, na concepção de Reale (2007, p. 167), significa "a forma de revelação do direito que se processa por meio do exercício da jurisdição, em virtude de uma sucessão harmônica de decisões dos tribunais".

Em conformidade o exposto acima, citamos a breve definição de Costa e Aquaroli (2003, p. 204), os quais definem jurisprudência como a "orientação uniforme dos tribunais na decisão de casos semelhantes".

Diniz (1992, p. 265) considera o termo jurisprudência como um

conjunto de decisões uniformes e constantes dos tribunais, resultante da aplicação de normas a casos semelhantes, constituindo uma norma geral aplicável a todas as hipóteses similares e idênticas. É o conjunto de normas emanadas dos juízes em sua atividade jurisdicional.

A jurisprudência, muitas vezes, inova em matéria jurídica, determinando normas que não se encontram exclusivamente nas leis, mas procedem de uma construção gerada por meio da conexão de dispositivos, até então considerados separadamente, ou ao contrário, mediante a separação de preceitos antes unidos entre si por longo tempo. Para nascer uma jurisprudência, é preciso certo número de decisões (julgadas) que coincidam quanto à essência das questões, objeto de seu pronunciamento.

Marques Junior (1997, p. 166) inclui como informação jurisprudencial os seguintes documentos:

a) Ação: direito que têm as pessoas (físicas ou jurídicas) de demandar ou pleitear em juízo, perante os tribunais, o que lhes pertence ou o que lhes é devido;

b) Sentença: decisão, resolução ou solução dada por uma autoridade a toda e qualquer questão submetida à sua jurisdição;

c) Recurso: provocação a um novo exame dos autos para emenda ou modificação da primeira sentença por meio de encaminhamento da questão ao próprio juiz, a outro juiz ou ao tribunal, podendo assumir, de acordo com a decisão, diferentes formas, tais como: apelação, embargo, agravo, revista, recurso extraordinário etc.;

d) Acórdão: resolução ou decisão tomada coletivamente pelos tribunais de justiça.

Alonso (1998) destaca a importância da jurisprudência como verdadeira fonte jurídica, capaz de esclarecer os conceitos gerais da norma legislativa se ajustando às particularidades dos fatos concretos. Nessa mesma visão, Guimarães (1993) apresenta que a jurisprudência constrói uma atividade interpretativa da lei, 
imprescindível quando surgem brechas no texto legal a ser aplicada ao caso concreto. Portanto, as publicações de jurisprudências são de extrema relevância para as bibliotecas jurídicas, haja vista a jurisprudência ser imprescindível aos juristas na fundamentação das suas decisões, pareceres etc.

Atualmente, quase todos os tribunais brasileiros facilitam o acesso a sua jurisprudência disponibilizando-a por meio das suas homepages, com busca de texto livre e as estratégias de busca sendo montadas com os conectivos lógicos (facilitadores utilizados como termos de ligação entre as palavras digitadas na pesquisa por assunto). 0 sucesso da pesquisa depende, basicamente, do uso correto dos conectivos: e; ou; prox. (proximidade); adj. (adjacência); mesmo; não. Vários desses conectivos podem ser utilizados simultaneamente.

\section{FONTES DE INFORMAÇÃO JURÍDICA NA INTERNET}

Atualmente, as pessoas utilizando bastante a ferramenta da internet, seja no campo profissional ou pessoal. A área jurídica foi bastante beneficiada com esses avanços oriundos do advento da internet, pois surgiram rapidamente sítios jurídicos que disponibilizam bases de dados abrangendo doutrina, texto integral de jurisprudência, legislação, acompanhamento processual, notícias do judiciário, portais de periódicos eletrônicos, revistas jurídicas digitais etc.

De acordo com Vergueiro (1997, p.61) a internet é considerada com um "conjunto de redes interligadas, com bilhões de dados, sem interesse duradouro". Cabendo ao bibliotecário avaliar a qualidade e a confiabilidade dos conteúdos, a fim de facilitar a busca e recuperação das informações solicitadas pela comunidade jurídica.

Dentre os principais produtores de fonte informação jurídica na internet, destacamos as Cortes Superiores: Supremo Tribunal Federal, Superior Tribunal de Justiça, Tribunal Superior do Trabalho, Tribunal Superior Eleitoral; os Tribunais de Justiça, Ministérios Públicos, Senado Federal, Câmara dos Deputados, Assembleias legislativas, Câmaras Legislativas, entre outros, que por meio de seus próprios sites disponibilizam mais rapidamente suas informações, com estratégias de busca montadas por intermédio de conectivos lógicos, facilitando a agilidade do acesso nas pesquisas, tendo em vista que vários sites jurídicos fornecem bases de dados com texto integral de legislação, Doutrina e Jurisprudência, Súmulas, acompanhamento processual etc.

A função do bibliotecário passou por algumas modificações ao longo dos últimos anos com o avanço da tecnologia e consequentemente com o advento da internet, conforme destaca Passos (2000, p.4) o papel do bibliotecário não se limita mais apenas em selecionar livros e periódicos impressos para incorporar ao acervo físico. Atualmente, seleciona também sites, bases de dados, blogs, páginas na internet que contemplam informações atualizadas e confiáveis que sejam relevantes para os usuários.

A modernização do avanço tecnológico, em especial a internet, tem promovido profundas mudanças nos procedimentos de produção, transmissão e acesso a informação, proporcionando diversos impactos positivos: 
Quadro1: Impactos da informação jurídica eletrônica.

\begin{tabular}{|cl|}
\hline$\checkmark$ & $\begin{array}{l}\text { acesso: rápido, amplo e minimização das diferenças geográficas e financeiras entre os } \\
\text { pesquisadores localizados em regiões distantes com baixo acesso a informação. }\end{array}$ \\
\hline$\checkmark$ & $\begin{array}{l}\text { armazenamento: grande potencial de armazenar e criar estoques, como banco de } \\
\text { dados de informação doutrinária, legislativa e jurisprudencial; }\end{array}$ \\
\hline$\checkmark$ & $\begin{array}{l}\text { atualização: propicia o monitoramento dos dados, favorecendo as decisões judiciais, } \\
\text { percepção crítica, abrangência e validação dos conteúdos acessados; }\end{array}$ \\
\hline$\checkmark$ & $\begin{array}{l}\text { busca: mais fácil e rápido por meio de ferramentas que racionalizam o tempo; e por } \\
\text { meio de computador, smartphone, tablet e um bom provedor; }\end{array}$ \\
\hline$\checkmark$ & custo: baixo para realização das pesquisas; \\
\hline$\checkmark$ & divulgação: possibilita a difusão do conhecimento de forma mais abrangente; \\
\hline$\checkmark$ & $\begin{array}{l}\text { geração de informação: possibilita maior obtenção de publicações ampliando em } \\
\text { quantidade e qualidade a produção intelectual dos juristas; }\end{array}$ \\
\hline$\checkmark$ & $\begin{array}{l}\text { periódicos jurídicos on line: permite acesso à pesquisa, que fornecem, agilidade e } \\
\text { precisão, uma visão completa sobre o assunto pesquisado e fundamentos sólidos } \\
\text { para a prática forense; }\end{array}$ \\
\hline
\end{tabular}

Fonte: Autor (2017).

Portanto, a internet possibilitou novas formas de obtenção da informação jurídica e pelo acesso em tempo real, imediato, garantindo maior agilidade na obtenção dos resultados da pesquisa, independente de sua localização geográfica.

As fontes de informação jurídicas exercem um papel importante no desempenho das atividades competentes do profissional de Direito. Para fins documentais, os sistemas de informação, bases de dados, sites e portais eletrônicos contribuem como ferramentas indispensáveis para auxiliar na busca e recuperação dos assuntos jurídicos pesquisados. (BARROS, 2004). 
Quadro 2: Sites jurídicos.

\begin{tabular}{|l|l|}
\hline Bibliotecas jurídicas virtuais & $\begin{array}{l}\text { bdjur.stj.jus.br/dspace } \\
\text { www.cjf.jus.br/biblioteca } \\
\text { www2.senado.gov.br/bdsf } \\
\text { bd.câmara.gov.br/bd }\end{array}$ \\
\hline Cursos jurídicos on-line & www.jurisway.com.br \\
\hline Diários oficiais & www.in.gov.br \\
\hline Doutrina & www.jus.com.br \\
\hline Informação jurídica & www.infolegis.com.br \\
\hline Jurisprudência estadual & $\begin{array}{l}\text { *todos os sites dos tribunais de justiça têm } \\
\text { sistemas de busca de sua jurisprudência }\end{array}$ \\
\hline Jurisprudência federal & $\begin{array}{l}\text { www.cjf.gov.br } \\
\text { columbo2.cjf.jus.br/juris/unificada }\end{array}$ \\
\hline Jurisprudência militar & www.stm.jus.br \\
\hline Jurisprudência da Suprema Corte & www.stf.jus.br \\
\hline Jurisprudência trabalhista & www.tst.jus.br \\
\hline Legislação ambiental & www.ibama.gov.br \\
\hline Legislação federal & $\begin{array}{l}\text { www.presidência.gov.br/legislação } \\
\text { www.lexml.gov.br }\end{array}$ \\
\hline $\begin{array}{l}\text { Legislação federal, estadual, distrital } \\
\text { municipal }\end{array}$ & www.interlegis.gov.br \\
\hline Legislação ou decisões eleitorais & www.tse.jus.br \\
\hline Legislação previdenciária & www81.dataprev.gov.br/sislex \\
\hline Legislação trabalhista & www.guiatrabalhista.com.br \\
\hline $\begin{array}{l}\text { Pesquisas em diversas formas } \\
\text { documentação jurídica }\end{array}$ & www.senado.gov.br \\
\hline $\begin{array}{l}\text { Artigos, notícias, } \\
\text { jurisprudência }\end{array}$ & $\begin{array}{l}\text { http://www.juridico.com.br/ } \\
\text { www.jusbrasil.com.br } \\
\text { www.conjur.com.br }\end{array}$ \\
\hline Projeto de lei & www.camara.gov.br \\
\hline Teses e dissertações na área do direito & http://www.teses.usp.br \\
\hline Textos de leis & www.soleis.adv.br \\
\hline Fonte: Adapta &
\end{tabular}

Fonte: Adaptado de Barros (2004. p. 212).

A legislação é a base primordial da informação jurídica, pois por intermédio dela é que os tribunais tomam suas decisões formando a jurisprudência e que é analisada formando a doutrina. Diante da sua importância, a disponibilização da legislação na internet e sua recuperação precisam ser de confiança e abrangentes.

\section{CONSIDERAÇÕES FINAIS}

Considerando a atual conjuntura da evolução tecnológica no mundo globalizado e o contínuo processo de constituição e de reconstituição das organizações exigem sistemas, processos, políticas e novas práticas sejam permanentemente aprimoradas. Numa sociedade competitiva, como a que se configura atualmente, o usuário da informação tem necessidade de respostas rápidas e eficientes que se transformam em importantes ferramentas para a tomada de decisões judiciais.

Diante desta complexidade e das mudanças na informação jurídica, percebemos a necessidade de o bibliotecário que atua na área jurídica ter conhecimento das estratégias adequadas de busca para localizar a informação solicitada em qualquer suporte, e atingir o principal objetivo de alcançar a satisfação dos usuários.

Em função do contexto observado, notou-se, que a informação jurídica é uma área profissional que vem expandindo nas últimas décadas, sobretudo que tem crescido na geração de novos conhecimentos. 
A maioria das fontes de informação jurídica é produzida pelos órgãos governamentais (Senado Federal; câmaras dos deputados; assembleias legislativas; câmara de vereadores; tribunais; ministérios públicos etc.) e o restante oriundo das pesquisas dos juristas através dos livros, teses, monografias, dissertações etc.

As fontes de informação jurídicas possuem um valor incalculável para o trabalho dos profissionais de Direito na execução das suas atividades. 0 bibliotecário jurídico precisa compreender esse valor e explorar com mais precisão as fontes de informação, visando a atingir uma melhor recuperação da informação e assim disseminá-la a toda comunidade jurídica.

A legislação é a base primordial da informação jurídica, pois por meio dela é que os tribunais tomam suas decisões formando a jurisprudência e que é analisada formando a doutrina. Diante da sua importância, a disponibilização da legislação na internet e sua recuperação precisam ser de confiança e abrangentes.

Desta forma, notou-se, que a proliferação de fontes de informação eletrônicas tornou a explosão bibliográfica ainda maior, diante do crescente volume de informações jurídicas disponibilizadas, na internet ou em outros meios de divulgação, cabe ao profissional bibliotecário figurar como mediador, sempre buscando e pesquisando meios facilitadores a fim de recuperar as informações úteis que atenda as necessidades de seus usuários.

Percebeu-se, que o acesso aos meios informacionais em suporte eletrônico expandiu as barreiras de recuperação da informação, para além dos acervos controlados mediantes critérios formais de qualidade, mas há necessidade de se reconhecer o valor do conteúdo existente em cada informação.

Portanto, constatou-se que, as fontes de informação eletrônicas minimizaram as diferenças geográficas e financeiras entre os pesquisadores localizados em regiões distantes e menos avançadas para sanar necessidades informacionais, além de permitir aos pesquisadores novas ferramentas adequadas permitindo ao usuário economizar tempo e dinamizar suas pesquisas.

\section{REFERÊNCIAS}

ALONSO, Cecília Andreotti Atienza. A informação jurídica face às comunidades da área do Direito e dos fornecedores da informação jurídica. In: Ciberética - Simpósio Internacional de Propriedade Intelectual, Informação e Ética, 1., 1998, Florianópolis. Anais... Florianópolis: ACB, 1998.

ANDRETA, Cássio Adriano. Legislação como assunto: uma proposta de extensão para a classificação decimal de Direito. In: PASSOS, Edilenice (Org.). Informação jurídica: teoria e prática. Brasília: Thesaurus, 2004.

ATIENZA, Cecília Andreotti. Documentação jurídica: introdução à análise e indexação de atos legais. Rio de Janeiro: Achiamé, 1979.

BARRETO, Aldo de Albuquerque. A questão da informação. Disponível em: <http://www.alternex.com.br/ aldoibct/quest/quest.htm>. Acesso em 25 jan.. 2013.

BARROS, Lucivaldo. Fontes de informação jurídica. In: PASSOS, Edilenice (Org.). Informação jurídica: teoria e prática. Brasília: Thesaurus, 2004.

BECKMAN, Clodoaldo; SILVA, Oneide. Fontes de informação. Belém: UFPA, 1967.

BOAVENTURA, Edivaldo M. Metodologia da pesquisa: monografia, dissertação, tese. São Paulo: Atlas, 2012. 
COSTA, Wagner Veneziani; AQUAROLI, Marcelo. Dicionário Jurídico. São Paulo: WVC Editora, 2003.

CUNHA, Murilo Bastos da; CAVALCANTI, Cordélia Robalinho de Oliveira. Dicionário de Biblioteconomia e Arquivologia. Brasília: Briquet de Lemos, 2010.

DINIZ, M. H. Compêndio de introdução à Ciência do Direito. 4. ed. São Paulo: Saraiva, 1992.

GIL, A. C. Métodos e técnicas de pesquisa social. 6. ed. São Paulo: Atlas, 2008.

GUIMARÃES, José Augusto Chaves. Elaboração de ementas de atos normativos: elementos de análise documentária como subsídio teórico à técnica legislativa. In: PASSOS, Edilenice (Org.). Informação jurídica: teoria e prática. Brasília: Thesaurus, 2004. p. 9-32.

GUIMARÃES, José Augusto Chaves. Formas da informação jurídica: uma contribuição rara sua abordagem temática. R. Bras. Bibliotecon. e Doc., São Paulo, v. 26, n. 1/2, p. 41-54, jan./jun.1993. Disponível em: < www.brapci.ufpr.br/download.php?dd0=19240>. Acesso em: 21 abr. 2012.

GUINCHAT, Claire; MENOU, Michel. Introdução às ciências e técnicas da informação e documentação. Brasília: IBICT, 1994.

LE COADIC, Yves-François. A ciência da informação. Brasília: Briquet de Lemos, 1996.

LOPEZ-MUÑIZ , Miguel Goni. Informática jurídica documental. Madrid: Diaz de Santos, 1984.

MARQUES JUNIOR, Alaôr Messias. Fontes de informação jurídico-legislativas. Perspectivas em Ciência da Informação, Belo Horizonte, v. 2, n. 2, p. 163 - 174, jul./dez. 1997. Disponível em: <http://portaldeperiodicos.eci.ufmg.br/index.php/pci/article/view/630/419>. Acesso em: 19 abr. 2016.

MARTINHO, Ana Maria. O bibliotecário jurídico: identidade e competências profissionais. In: Encontro Nacional de Bibliotecas Jurídicas, 1., 2004. Anais... Lisboa: Faculdade de Direito da Universidade de Lisboa, 2004.

MIRANDA, Ana Cláudia Carvalho de. A política de desenvolvimento de coleções no âmbito da informação jurídica. In: PASSOS, Edilenice (Org.). Informação jurídica: teoria e prática. Brasília: Thesaurus, 2004.

Critérios de avaliação para coleções de periódicos. In: Seminário Nacional de Bibliotecas Universitárias, 13., 2004, Natal. Anais... Natal: UFRN, 2004. 1 CD.

A Qualidade enquanto instrumento na política de desenvolvimento de coleções jurídicas. In: Ciberética, 2., 2003, Florianópolis. Anais eletrônicos... Florianópolis: ACB, 2003. Disponível em: <http://www.ciberetica.org.b/trabalhos/anais/7-13-el-13.pdf>. Acesso em 15 jul. 2004.

MONTORO, A. F. Introdução à Ciência do Direito. 25. ed. São Paulo: Revista dos tribunais, 2000.

MUELLER, Suzana Pinheiro Machado. A ciência, o sistema de comunicação científica e a literatura científica. In: CAMPELO, Bernadete Santos (Org.). Fontes de informação para pesquisadores e profissionais. Belo Horizonte: UFMG, 2000.

OBERHOFER, Cecília Malizia A. Valor da informação: percepção versus quantificação. Ciência da informação, Brasília, v.20, n.2, p. 119-129, jul./dez. 1991. 
PASSOS, Edilenice. Bibliotecário jurídico: seu perfil, seu papel. Disponível em: <http://www.infolegis.com.br/perfilbibjridico.htm>. Acesso em 26 jan. 2013.

; BARROS, Lucivaldo Vasconcelos. Fontes de informação para pesquisa em direito.

Brasília: Briquet de Lemos, 2009.

O controle da informação jurídica no Brasil: a contribuição do Senado Federal. Ciência da informação, Brasília, v.23, n.3, p. 363-368, set./dez. 1994.

REALE, Miguel. Lições preliminares de Direito. 24. ed. São Paulo: Saraiva, 1998.

REZENDE, Martha de Souza Duarte. Gerenciamento da informação e do conhecimento no escritório de advocacia. In: Ciberética - Simpósio Internacional de Propriedade Intelectual, Informação e Ética, 1., 1998, Florianópolis. Anais... Florianópolis: ACB, 1998.

SARMENTO, Adriana Godoy da Silveira; ROSA, Alpina Gonzaga Martins; FERREIRA, Regina de Marco. Informação jurídica: valor agregado. O quê? Por quem? E para quem? In: CONGRESSO BRASILEIRO DE BIBLIOTECONOMIA E DOCUMENTAÇÃO, 19., 2000, Porto Alegre. Anais... Porto Alegre: PUCRS, 2000. 1 CD.

SILVA, Andréia Gonçalves. Fontes de informação jurídica: conceitos e técnicas de leitura para o profissional da informação. Rio de Janeiro: Interciência, 2010.

TOMAÉL, Maria Inês (org.). Fontes de informação na internet. Londrina: Eduel, 2008.

VALENTIM, Marta Lígia Pomim. Inteligência competitiva em organizações: dado, informação e conhecimento. DataGramaZero, Rio de Janeiro, v. 3, n. 4, ago. 2002. Disponível em: < http://www.dgz.org.br/ago02/Art_02.htm >. Acesso em: 14 maio. 2014. 